\title{
LA RESPONSABILIDAD EXTRACONTRACTUAL POR ILÍCITOS ANTITRUST EN EUROPA. COMENTARIO DEL AUTO DEL JUZGADO DE LO MERCANTIL DE MADRID, DE 23 MAYO 2018
}

\author{
THE NON-CONTRACTUAL LIABILITY FROM EUROPEAN \\ ANTITRUST LAW INFRINGEMENTS. COMMENTARY OF \\ DECISION OF COMMERCIAL COURT OF MADRID, OF 23 MAY 2018
}

\author{
JULIANA RoDRÍGUEZ RODRIGO \\ Profesora Titular de Derecho Internacional Privado \\ Universidad Carlos III de Madrid \\ ORCID ID: 0000-0002-5896-983X
}

Recibido: 08.01.2019 / Aceptado: 25.01.2019

DOI: https://doi.org/10.20318/cdt.2019.4664

\begin{abstract}
Resumen: El Auto del Juzgado de lo Mercantil de Madrid, objeto de comentario en este trabajo, resuelve una declinatoria por falta de jurisdicción en un caso de reclamación de daños por un ilícito antitrust. El comportamiento anticompetitivo del que derivan los perjuicios, que ahora se reclaman, es el conocido como cártel de los camiones, que sancionó la Comisión Europea en el año 2016. Una de las víctimas de ilícito antitrust pide una indemnización por los daños y perjuicios sufridos por el hecho de haber tenido que pagar un sobreprecio en la compra de uno o varios camiones objetos del acuerdo colusorio. El Juzgado de lo Mercantil de Madrid rechaza la declinatoria por hallarse el domicilio de la demandada en territorio español.
\end{abstract}

Palabras clave: aplicación privada del Derecho de la competencia, acciones follow on, cártel de los camiones, indemnización por daños derivados de un ilícito antitrust, foro del lugar del hecho ilícito, foro del lugar del daño.

Abstract: The Decision of Commercial Court of Madrid, object of comment in this paper, resolves a declinatory for lack of jurisdiction in a case of claim of damages from European antitrust law infringement. The anticompetitive behavior from which the damages derive is known as the truck cartel, which was sanctioned by the European Commission in 2016. One of the victims of this behavior seeks compensation for the damages suffered by the fact of having to pay a surcharge in the purchase of one or more trucks that belong to scope of collusive agreement. The Commercial Court of Madrid rejects the declinatory because the defendant's domicile is located in Spanish territory.

Keywords: private enforcement of competition law, follow on actions, cartel of trucks, compensation for damages from European antitrust law infringement, forum of place in which the harmful event occurred, forum of place of damage.

Sumario: I. Introducción; II. Aplicación privada del Derecho europeo de la competencia. 1. Aplicación pública y privada del Derecho europeo de la competencia. 2. Finalidad de ambas acciones. 3. Acciones follow on y acciones stand alone. III. Competencia judicial internacional. 1. Supuestos internacionales. 2. Reglamento 1215/2012. A. Reglamento 1215/2012: foro de sumisión. B. Reglamento 1215/2012: foro general del domicilio del demandado y foro especial por razón de la materia. IV. Bibliografía. 


\section{Hechos del caso}

1. En el Auto a comentar, el Juzgado de lo Mercantil de Madrid debe resolver si tiene competencia para conocer de una demanda de responsabilidad civil que plantea la empresa Carretillas Barcelona S.L. contra Volvo Group España S.A.U., por el sobreprecio pagado por la primera en la compra de un camión vendido por una empresa participante en el denominado cártel de los camiones ${ }^{1}$.

2. Las cuestiones que van a ser tratadas en este trabajo son las dos siguientes. En primer lugar, debemos poner en contexto al lector y, para ello, vamos a explicar la aplicación privada del Derecho europeo de la competencia para regular la reclamación de los daños y perjuicios ocasionados por ilícitos antitrust -el cártel de los camiones en nuestro caso, sancionado por la Comisión en virtud del artículo 101 TFUE $^{2}$. En segundo lugar, una vez conocemos que existe esa posibilidad de reclamar daños ante la jurisdicción civil, debemos saber qué órganos jurisdiccionales son los competentes para conocer de estas demandas civiles -competencia judicial internacional-.

\section{Aplicación privada del Derecho europeo de la competencia}

\section{Aplicación pública y aplicación privada del Derecho europeo de la competencia}

3. Las empresas que infringen el Derecho de la competencia pueden ser sancionadas por dos vías, la administrativa y la civil ${ }^{3}$.

En efecto, por un lado, pueden ser destinatarias de una multa impuesta por el órgano competente en esta materia (arts. 4 y 5 Reglamento 1/2003). Este órgano puede ser la Comisión Europea o la autoridad nacional de competencia correspondiente -en España es la Comisión Nacional de los Mercados y la Competencia-. La aplicación del Derecho de la competencia que realiza este órgano administrativo se denomina aplicación pública.

Por otro lado, las víctimas del comportamiento anticompetitivo deben poder ser resarcidas del daño sufrido, por ello, pueden plantear una reclamación de daños y perjuicios para recibir una indemnización en la vía civil (art. 6 y Considerando 7 del Reglamento 1/2003). La autoridad competente en este caso es el órgano jurisdiccional civil correspondiente y la aplicación del Derecho de la competencia que realiza es la aplicación privada. En este proceso de daños, las decisiones firmes de las autoridades nacionales de competencia y de los órganos jurisdiccionales nacionales serán consideradas como prueba irrefutable de la existencia e ilicitud del comportamiento ilícito (art. 9.1 de la Directiva de daños) ${ }^{4}$.

\footnotetext{
${ }^{1}$ Auto JM Madrid 23 mayo 2018, ECLI:ES:JMM:2018:65A

2 Decisión de la Comisión de 19 julio 2016, relativa a un procedimiento de aplicación del artículo 101 del TFUE y del artículo 53 del Acuerdo del EEE ( AT.39824 -Trucks), Bruselas, 19 julio 2016, C(2016) 4673 final.

3 Vid., A. Calvo Caravaca/J. Carrascosa GonzÁlez, El Derecho Internacional privado de la Unión Europea frente a las acciones por daños anticompetitivos, CDT, vol. 10, $\mathrm{n}^{\circ}$ 2, 2018, p. 9; J. SuDERow, Acciones derivadas de ilícitos antitrust: el foro especial de la obligación extracontractual después de la sentencia CDC Hydrogen Peroxide, CDT, vol. 8, nº 2, 2016 , p. 307.

El Reglamento 1/2003 es la norma que introduce la descentralización en la aplicación del Derecho antitrust (Reglamento (CE) $n^{\circ} 1 / 2003$ del Consejo, de 16 diciembre 2002, relativo a la aplicación de las normas sobre competencia previstas en los artículos 81 y 82 del Tratado, DOCE $n^{\circ}$ L1, de 4 enero 2003). Así es, este texto europeo dispone que, frente a la competencia exclusiva de la Comisión para aplicar el artículo 81.3 TCE recogida en el antiguo Reglamento $\mathrm{n}^{\circ}$ 17, las autoridades nacionales de competencia y los órganos jurisdiccionales nacionales serán competentes para aplicar los artículos 81 y 82 TCE -actuales artículos 101 y 102 TFUE- (Reglamento $n^{\circ}$ 17, de 6 febrero 1962, primer reglamento de aplicación de los artículos 85 y 86 del Tratado, DOCE n ${ }^{\circ}$ 13, de 21 febrero 1962) (vid., en este sentido, M. DANOv/F. BECKER, Governance Aspects of Cross-Border EU Competition Actions: Theoretical and Practical Challenges, Journal of Private International Law, vol. 10, $\mathrm{n}^{\circ} 3$, 2014, p. 359). Los órganos jurisdiccionales nacionales, a los que hace referencia el Reglamento 1/2003, en el caso español son los juzgados de lo mercantil, según recoge la Disposición Adicional Primera de la Ley de Defensa de la Competencia 15/2007, de 3 de julio, en relación con el artículo 86. ter 2 letra f de la Ley Orgánica 6/1985, del Poder Judicial (Ley 15/2003, de 3 de julio, de Defensa de la Competencia, publicada en el BOE núm. 159, de 4 julio 2007).

${ }^{4}$ Directiva 2014/104/UE del Parlamento Europeo y del Consejo, de 26 noviembre 2014, relativa a determinadas normas por las que se rigen las acciones por daños en virtud del Derecho nacional, por infracciones del Derecho de la competencia de los Estados miembros y de la Unión Europea, DO L349, de 5 diciembre 2014.
} 
4. La sanción administrativa es independiente de la civil. Tan es así, que es posible que la empresa infractora no tenga que pagar multa alguna $\mathrm{y}$, sin embargo, ello no obsta para que se le pueda exigir responsabilidad civil por su comportamiento ${ }^{5}$. Efectivamente, si la empresa se acoge al Programa de Clemencia de la Unión Europea puede ocurrir que no tenga que pagar la multa impuesta, sin embargo, sí podría ser requerida para que pague la indemnización civil por los daños y perjuicios ocasionados ${ }^{6}$. No obstante lo anterior, la Directiva de daños contempla que los beneficiarios de clemencia no respondan de forman solidaria frente a las víctimas, como sí hacen el resto de infractores del Derecho de la competencia, sino que limiten su responsabilidad civil, con carácter general, sólo a las indemnizaciones a pagar a sus compradores directos e indirectos (art. 11.4) ${ }^{7}$.

En los ordenamientos en los que se exige la culpabilidad de las empresas infractoras para indemnizar el daño, no concurriría este requisito si la entente se acoge a la exención del artículo 101.3 TFUE y no es objeto de sanción ${ }^{8}$. Lo mismo se debe decir cuando las empresas destinatarias de un pliego de cargos de la Comisión, proponen acuerdos para despejar las dudas del órgano europeo sobre la ilicitud de su comportamiento ${ }^{9}$. Tampoco habría culpabilidad si la Comisión acepta esos acuerdos propuestos por las empresas ${ }^{10}$.

5. El plazo para iniciar la acción por daños debe ser, al menos, de cinco años; según prescribe la Directiva 2014/104 ${ }^{11}$. La Ley de transposición española de la Directiva, concretamente, recoge ese plazo de 5 años a contar a partir del momento del cese de la infracción y cuando el demandante conozca la existencia del comportamiento anticompetitivo, del daño sufrido y de la identidad del infractor ${ }^{12}$.

\section{Finalidad de ambas vías de actuación}

6. La vía administrativa persigue sancionar a las empresas por el comportamiento ilícito llevado a cabo y disuadirlas de que vuelvan a infringir el Derecho de la competencia.

Vid., en este sentido, A.L. Calvo CARaVACa/J. Suderow, El efecto vinculante de las resoluciones de las autoridades nacionales de competencia en la aplicación privada del derecho antitrust, CDT, vol. 7, nº 2, 2015, pp. 114-157; C. Herrero SUÁREZ, La transposición de la Directiva de daños antitrust, Reflexiones a raiz de la publicación de la Propuesta de Ley de transposición de la Directiva, CDT, vol. 8, nº 1, 2016, pp. 168-169.

${ }^{5}$ R. Gil Nievas, Litigación civil internacional por daños derivados de infracciones del Derecho de la competencia, Revista de Derecho de la competencia y la distribución, $\mathrm{n}^{\circ}$ 4, 2009, p. 145.

${ }^{6}$ La Comunicación de la Comisión relativa a la dispensa del pago de las multas y la reducción de su importe en casos de cártel prevé que "la Comisión dispensará del pago de la multa que de otro modo se le hubiera impuesto a toda empresa que revele su participación en un presunto cártel que afecte a la Comunidad cuando sea la primera en facilitar información y elementos de prueba que, a juicio de la Comisión, permitan a ésta: a) efectuar una inspección oportunamente orientada sobre el presunto cártel o; b) determinar la existencia de una infracción al artículo 81 del Tratado CE en relación con el presunto cártel' (Apartado II, Sección A, punto 8) (DOCE n C298, de 8 diciembre 2006, pp. 17-22).

7 Vid., en este sentido, D. BECKER, Les actions en dommages et intérêts pour infraction au droit de la concurrence européen, ACE, comptabilité, fiscalité, audit, droit des affaires au Luxembourg, $\mathrm{n}^{\circ}$ 2, 2009, p. 28; M. ChaGNY, L'articulation entre actions privées et actions publiques, Revue Lamy de la concurrence, $\mathrm{n}^{\circ}$ 18, 2009, p. 120.

${ }^{8} \mathrm{M}$. Chagny, L'articulation entre actions privées et actions publiques, Revue Lamy de la concurrence, $\mathrm{n}^{\circ}$ 18, 2009, p. 120.

${ }^{9}$ M. Chagny, L'articulation entre actions privées et actions publiques, Revue Lamy de la concurrence, $\mathrm{n}^{\circ}$ 18, 2009, p. 120.

${ }^{10}$ M. Chagny, L'articulation entre actions privées et actions publiques, Revue Lamy de la concurrence, $\mathrm{n}^{\circ}$ 18, 2009, p. 120.

${ }^{11}$ C. Herrero SuÁrez, La transposición de la Directiva de daños antitrust, Reflexiones a raiz de la publicación de la Propuesta de Ley de transposición de la Directiva, CDT, vol. 8, n 1, 2016, p. 170.

${ }^{12}$ Artículo 74 de la Ley 15/2007, de 3 de julio, de Defensa de la Competencia, en materia de ejercicio de las acciones de daños y perjuicios por infracciones del Derecho de la competencia, modificado por el Real Decreto-Ley 9/2017, de 26 mayo, por el que se transponen directivas de la Unión Europea en los ámbitos financieros, mercantil y sanitario, y sobre el desplazamiento de trabajadores, BOE núm. 126, de 27 mayo 2017: "1. La acción para exigir la responsabilidad por los daños y perjuicios sufridos como consecuencia de las infracciones del Derecho de la competencia prescribirá a los cinco años. 2. El cómputo del plazo comenzará en el momento en el que hubiera cesado la infracción del Derecho de la competencia y el demandante tenga conocimiento o haya podido razonablemente tener conocimiento de las siguientes circunstancias: a) La conducta y el hecho de que sea constitutiva de una infracción del Derecho de la competencia; b) el perjuicio ocasionado por la citada infracción; y c) la identidad del infractor. 3. El plazo se interrumpirá si una autoridad de la competencia inicia una investigación o un procedimiento sancionador en relación con una infracción del Derecho de la competencia relacionados con la acción de daños. La interrupción terminará un año después de que la resolución adoptada por la autoridad de competencia sea firme o se dé por concluido el procedimiento de cualquier otra forma. 4. Asimismo se interrumpirá el plazo cuando se inicie cualquier procedimiento de solución extrajudicial de controversias sobre la reclamación de los daños y perjuicios ocasionados. La interrupción, sin embargo, solo se aplicará en relación con las partes que estuvieran inmersas o representadas en la solución extrajudicial de la controversia." 
A través de la vía civil se busca, en cambio, el resarcimiento de los perjuicios sufridos por las víctimas del ilícito antitrust. En efecto, en virtud de la Directiva de daños, la víctima tiene derecho al pleno resarcimiento, lo cual implica que reciba una indemnización que la sitúe en la misma posición que tendría de no haberse llevado a cabo el comportamiento ilícito (art. 3). Esto es, el pleno resarcimiento supone compensar el daño emergente y el lucro cesante, más los intereses devengados ${ }^{13}$.

7. Como acabamos de mencionar, la aplicación pública del Derecho de la competencia tiene como objetivo, entre otros, disuadir a las empresas de volver a infringir el Derecho antitrust. Sin embargo, desde el momento en que las Directrices europeas para el cálculo de las multas fijan el máximo de las mismas en el 10\% del volumen de negocio de la empresa en el ejercicio anterior, dicho efecto disuasorio puede no concurrir en muchos casos ${ }^{14}$.

En la vía civil, a través del resarcimiento de daños y perjuicios, en cambio, no hay ningún límite máximo en la cuantía de la indemnización. Además, como ya se ha mencionado, las empresas infractoras del Derecho de la competencia responden en régimen de solidaridad, por lo tanto, la víctima puede reclamar los daños a cualquiera de ellas, sin importar que la demandada sea la empresa que le ha infligido el daño o sea otra participante en el cártel (art. 11 de la Directiva de daños).

Por todo lo dicho anteriormente, la esperanza del efecto disuasorio se encuentra en la vía civil, en la indemnización por los daños sufridos que deben pagar las empresas infractoras del Derecho antitrust $^{15}$.

8. La responsabilidad conjunta y solidaria frente a las víctimas tiene una excepción, que ya se ha mencionado anteriormente. Efectivamente, cuando la autoridad administrativa haya actuado por la información facilitada por una de las empresas infractoras del Derecho de la competencia, esto es, cuando haya alguna compañía que se haya beneficiado del programa de clemencia por haber proporcionado información relevante del comportamiento ilícito y, así, haber obtenido una reducción en la multa o, incluso, la total inmunidad, esta empresa no va a responder de forma solidaria con las demás. Así es, para favorecer la delación y el conocimiento por parte de la autoridad administrativa de la existencia de comportamientos lesivos de la competencia y, así, poder reprimirlos, el legislador europeo recoge que las empresas que se acojan al programa de clemencia sólo respondan por los daños efectivamente realizados por ellas ${ }^{16}$.

En el caso del Auto del Juzgado de lo Mercantil de Madrid que estamos comentando, la investigación de la Comisión Europea se inició por la información recibida de MAN. Esta empresa se acogió al programa de clemencia y consiguió la inmunidad, esto es, el $100 \%$ de reducción de la multa por la información facilitada. Volvo-Renault obtuvo el $40 \%$ de reducción, Daimler-Mercedes el $30 \%$ e Iveco el $10 \%$. El porcentaje aplicado depende de la relevancia de la información suministrada al órgano de competencia.

${ }^{13}$ C. Herrero SuÁrez, La transposición de la Directiva de daños antitrust, Reflexiones a raiz de la publicación de la Propuesta de Ley de transposición de la Directiva, CDT, vol. 8, nº 1, 2016, p. 172.

${ }^{14}$ Directrices para el cálculo de las multas impuestas en aplicación del artículo 23, apartado 2, letra a), del Reglamento (CE) n 1/2003, DO C210, de 1 septiembre 2006. Punto 32: "Por cada empresa o asociación de empresas que participen en la infracción, la multa no podrá superar el $10 \%$ del volumen de negocios total realizado durante el ejercicio social anterior, de conformidad con lo dispuesto en el artículo 23, apartado 2, del Reglamento (CE) $n^{\circ} 1 / 2003$ ".

${ }^{15}$ Vid., en este sentido, C. Fratea, Los primeros pronunciamientos del Tribunal de Justicia de la Unión sobre Europea la aplicación privada del Derecho de la competencia y sus reflejos sobre la competencia judicial en las acciones indemnizatorias en Europa, AEDIP, t. XVI, 2016, p. 645.

${ }^{16}$ C. Herrero SuÁrez, La transposición de la Directiva de daños antitrust, Reflexiones a raiz de la publicación de la Propuesta de Ley de transposición de la Directiva, CDT, vol. 8, n 1, 2016, p. 171.

En concreto, según el artículo 11.4 de la Directiva de daños, "Como excepción al apartado 1, los Estados miembros velarán por que un beneficiario de clemencia sea responsable: a) ante sus compradores o proveedores directos o indirectos, y b) ante otras partes perjudicadas solo cuando no se pueda obtener el pleno resarcimiento de las demás empresas que estuvieron implicadas en la misma infracción del Derecho de la competencia. [...]”.

Algunos autores consideran que habría sido mejor que la Directiva hubiera regulado la inmunidad o reducción de la cuantía a pagar por los daños, de las empresas infractoras beneficiarias del programa de clemencia (P. KIRST/R. VAN DEN BERGH, The European Directive on damages actions: a missed opportunity to reconcile compensation of victims and leniency incentives, Journal of Competition Law \& Economics, $\mathrm{n}^{\circ}$ 1, 2016, pp. 17 y ss). 


\section{Acciones follow on y acciones stand alone}

9. En este caso del Juzgado de lo Mercantil, la Comisión Europea se ocupó de la aplicación pública del Derecho de la competencia. En su Decisión consideró que cinco empresas fabricantes de camiones -DAF, MAN, Daimler-Mercedes, Volvo-Renault e Iveco- habían llevado a cabo un acuerdo colusorio en virtud del cual habían pactado no competir entre ellas en el Espacio Económico Europeo desde el año 1997 hasta el año 2011 ${ }^{17}$. Durante esos 14 años elevaron el precio de sus camiones de forma artificial y perjudicaron a los compradores, que tuvieron que pagar un sobreprecio que no tendrían que haber abonado de no haber llegado los fabricantes de camiones a ese acuerdo ilícito.

10. La acción interpuesta ante el Juzgado de lo Mercantil de Madrid es una acción follow on. Así es, cuando se trata de la aplicación privada del Derecho de la competencia podemos hablar de dos tipos de acciones, las follow on y las stand alone $e^{18}$. Las primeras son aquellas que se plantean ante la jurisdicción civil después de que la autoridad administrativa se haya pronunciado calificando como ilícito el comportamiento anticompetitivo llevado a cabo. Las acciones stand alone son las que se inician sin que haya todavía ningún pronunciamiento administrativo en relación con el comportamiento antitrust. Respecto de estas últimas, acudiendo a las normas de producción interna españolas, lo primero que comprobamos es que, si bien la derogada Ley 16/1989 de Defensa de la Competencia sí prescribía la necesidad de que existiera un pronunciamiento administrativo previo sobre la ilicitud del comportamiento causante del daño, la actual Ley 15/2007, de Defensa de la Competencia, no recoge nada sobre el particular ${ }^{19}$. Por lo tanto, se confirma que es posible, como ya hemos adelantado, que se inicie un proceso de reclamación de daños sin que haya habido un pronunciamiento en relación con la infracción del Derecho de la competencia.

11. En la práctica de los tribunales, son muchas más las acciones follow-on que las stand alone ${ }^{20}$. Entre otras razones, por la dificultad que plantea la prueba de los hechos contrarios al Derecho antitrust en estas últimas ${ }^{21}$. Esto es, en este tipo de acciones, la víctima debe probarlo todo, el hecho ilícito -el comportamiento anticompetitivo-, el daño sufrido y la relación de causalidad. Sin embargo, cuando se trata de acciones follow on, el demandante sólo tiene que probar su daño, ya que, por un lado, el hecho ilícito ya estará demostrado en la resolución administrativa y, por otro, la relación de causalidad se presume. Así es, en relación con esto último, la Directiva de daños establece la presunción de que los cárteles causan daños y perjuicios e invierte la carga de la prueba al estipular que será el infractor el que rebata lo anterior (art. 17.2).

${ }^{17}$ Decisión de la Comisión de 19 julio 2016, relativa a un procedimiento de aplicación del artículo 101 del TFUE y del artículo 53 del Acuerdo del EEE ( AT.39824 -Trucks), Bruselas, 19 julio 2016, C(2016) 4673 final.

18 J. Suderow, Acciones derivadas de ilícitos antitrust: el foro especial de la obligación extracontractual después de la sentencia CDC Hydrogen Peroxide, CDT, vol. 8, n 2, 2016, p. 309.

${ }^{19}$ Ley 15/2007, de 3 julio, de Defensa de la Competencia, BOE núm. 159, de 4 julio 2007.

Ley 16/1989, de 17 julio, de Defensa de la Competencia, BOE núm. 170, de 18 julio 1989. Artículo 13: “1. Las sanciones a que se refiere la presente Ley se entenderán sin perjuicio de otras responsabilidades que en cada paso procedan. 2. La acción de resarcimiento de daños y perjuicios, fundada en la ilicitud de los actos prohibidos por esta Ley, podrá ejercitarse por los que se consideren perjudicados, una vez firme la declaración en vía administrativa y, en su caso, jurisdiccional. El régimen sustantivo y procesal de la acción de resarcimiento de daños y perjuicios es el previsto en las leyes civiles."

${ }^{20}$ Vid., F. Marcos/A. SÁnchez Graells, Towards a European Tort Law? Damages actions for breach of the EC Antitrust Rules: Harmonizing Tort Law through the Back Door?, European Review of Private Law, vol. 16, núm. 3-2008, pp. 479-480; J. SuDERow, Acciones derivadas de ilícitos antitrust: el foro especial de la obligación extracontractual después de la sentencia CDC Hydrogen Peroxide, CDT, vol. 8, nº 2, 2016, pp. 309.

${ }^{21}$ Vid., R. Gil Nievas, Litigación civil, cit., p. 160. En cuanto a la dificultad probatoria en los procesos de Derecho de la competencia, vid., entre otros, B. CAVALlone, "Azioni di risarcimento del danno per violazione delle norme antitrust comunitarie: problema dell'istruzione probatoria", en F. Rossi daL Pozzo/B. NASCIMBENE (eds.), Il private enforcement delle norme sulla concorrenza, Giuffrè, Milano, 2009, pp. 31-39; B. ButTAzzI, "Il libro bianco 2008 della Commissione europea: un passo avanti per le azioni di risarcimento antitrust?, Rivista Trimestrale di Diritto e Procedura Civile, LXIII, 3, 2009, pp. 1087-1090; R. Becker/N. Bessot/E. de Smijter, "The White Paper on damages actions for breach of the EC Antitrust rules", en C. Gheur/N. Petit (eds.), Alternative enforcement techniques in EC Competition Law, Bruylant, Bruxelles, 2009, p. 22. En relación a los procesos de abuso de posición de dominio, vid., E. BRODI, "Illecito antitrust e risarcimento del danno in alcuni recenti casi di abuso di posizione dominante", R. soc., 53, 6, 2008, pp. 1440-1486. 
Las acciones stand alone han quedado, por tanto, para "casos en los que la víctima y el infractor mantienen una relación directa, probablemente contractual, y en los que se encuentran involucrados sustanciales intereses económicos"22.

\section{Competencia judicial internacional en las acciones por daños}

\section{Supuestos internacionales}

12. Como ya sabemos, por lo explicado hasta ahora, la aplicación privada del Derecho de la competencia la realizan los órganos jurisdiccionales nacionales. No obstante, en supuestos de ilícitos antitrust internacionales, esto es, en la mayoría de los casos de infracción del Derecho europeo de la competencia, cabría preguntarse inmediatamente, qué Estado es aquel en el que se encuentran los jueces competentes para conocer de una demanda de reclamación de daños en este marco.

13. Las acciones por daños derivados de ilícitos antitrust, normalmente, son internacionales. Así es, lo habitual es que en ellas haya algún elemento de extranjería. En un mundo globalizado, como es en el que nos encontramos, y con los avances tecnológicos de los que nos estamos beneficiando, es fácil encontrar ilícitos antitrust internacionales y relaciones de daños derivados de ellos, también, de carácter internacional ${ }^{23}$.

El caso comentado es un claro ejemplo de un ilícito antitrust internacional con consecuencias civiles internacionales. En efecto, el cártel de los camiones es un acuerdo entre cinco empresas de diferentes nacionalidades y domicilios, que actuó en todo el Espacio Económico Europeo y que ha generado daños a clientes de distintas nacionalidades y domicilios.

14. En nuestro supuesto, la víctima tiene su domicilio en España -Carretillas Barcelona S.A.-, el demandado es una entidad con domicilio social en España, según consta en el Auto - Volvo Group España S.A.U.-, el hecho ilícito se ha verificado en Europa -más adelante intentaremos identificar el lugar concreto- y el daño en España. El elemento de extranjería es, por tanto, el hecho ilícito -el cártel de los camiones- del que deriva el daño.

15. Teniendo en cuenta la identidad del demandado es importante destacar un aspecto al que hace referencia el Auto del Juzgado de lo Mercantil de Madrid, cual es, a quién puede reclamar la víctima la indemnización por los daños sufridos -legitimación pasiva-.

El Auto recoge que el demandado alega que no es una de las empresas que aparece en la Decisión de la Comisión como destinatarias de la multa por la infracción del Derecho europeo de la competencia. Efectivamente, Volvo Group España S.A.U. no es una de las compañías a las que sanciona el órgano europeo de competencia. Las entidades del Grupo Volvo-Renault que aparecen en la Decisión son las siguientes: AB Volvo (publ), Volvo Lastvagnar AB, Renault Trucks SAS y Volvo Group Trucks Central Europe GmbH. Por tanto, habría que plantearse cuál es la legitimación pasiva en estos casos de reclamación de daños por ilícitos antitrust. Esto es, si, por ejemplo, se podría alegar la doctrina del levantamiento del velo en estos supuestos para demandar solamente a los verdaderos responsables del ilícito antitrust o si, por el contrario, se podría demandar a filiales infractoras aún cuando realmente no tengan independencia y se encuentren controladas por la matriz.

En este sentido la doctrina se encuentra muy dividida ${ }^{24}$. Sin embargo, cuando la Directiva de daños define al infractor diciendo que es la empresa que ha cometido una infracción del Derecho de la

${ }^{22}$ F. Marcos/A. SÁnchez Graells, Towards a European Tort Law? Damages actions for breach of the EC Antitrust Rules: Harmonizing Tort Law through the Back Door?, European Review of Private Law, vol. 16, núm. 3-2008, p. 480.

${ }^{23}$ C. FRATEA, Los primeros pronunciamientos del Tribunal de Justicia de la Unión sobre Europea la aplicación privada del Derecho de la competencia y sus reflejos sobre la competencia judicial en las acciones indemnizatorias en Europa, AEDIP, t. XVI, 2016, p. 645.

${ }^{24}$ A.L. Calvo Caravaca/J. Carrascosa González, El Derecho Internacional privado de la Unión Europea frente a las acciones por daños anticompetitivos, CDT, vol. 10, $\mathrm{n}^{\circ} 2,2018$, pp. $130 \mathrm{y}$ ss. 
competencia (art. 2.2), podría interpretarse en este marco que se deben reclamar los daños y perjuicios sufridos al infractor, esto es, a la empresa que sea la autora/responsable de la infracción ${ }^{25}$. La jurisprudencia del Tribunal de Justicia, en casos como Akzo o Siemens Österreicht, apoya esta opinión, si bien, en estos asuntos se trataba de la aplicación pública del Derecho de la competencia y, por ende, de la responsabilidad del grupo a estos efectos ${ }^{26}$.

16. Lo que podría presumirse en nuestro caso es que Volvo Group España puede ser la filial española de alguna de las entidades multadas por la Comisión. No podría considerarse que se trata de una sucursal porque el Auto indica que tiene domicilio y que se encuentra en España. Las sucursales, agencias $\mathrm{u}$ otros establecimientos secundarios no tienen domicilio propio, al ser dependientes de la matriz su domicilio es el de la matriz, forman parte de ella.

Si se tratara de una filial, el Juzgado de lo Mercantil estaría permitiendo demandar, ante los tribunales de su domicilio, a una entidad que no es la responsable del comportamiento antitrust puesto que no es la destinataria de la multa administrativa. No está, por tanto, siguiendo la doctrina de la unidad económica de la aplicación pública del Derecho de la competencia y está aplicando el artículo 4 del Reglamento 1215/2015 en estado puro, tratando a cada persona jurídica como potenciales demandados separados, sin tener en cuenta, por tanto, los vínculos económicos y jurídicos y la relación de dependencia y control que les puedan unir ${ }^{27}$.

\section{Reglamento 1215/2012}

17. En el caso del Auto comentado, el Reglamento $1215 / 2012$ es la norma aplicable para determinar la competencia judicial internacional en relación con la demanda de daños planteada ${ }^{28}$. En efecto, esta norma se aplica a la materia civil y mercantil, y las reclamaciones de daños por ilícitos antitrust son calificadas como cuestiones civiles y mercantiles a estos efectos ${ }^{29}$.

18. Según este texto europeo, son tres los foros que pueden utilizarse para dar competencia en este tipo de reclamación. En primer lugar habrá que tener en cuenta el foro de sumisión. En segundo lugar, en defecto del anterior, podrían aplicarse el foro general del domicilio del demandado y foro especial por razón de la materia ${ }^{30}$.

${ }^{25}$ C. HeInze, Los acuerdos atributivos de jurisdicción y la ejecución efectiva del Derecho de la competencia de la UE. Algunas precisiones sobre el alcance de los acuerdos de jurisdicción tras la sentencia del Tribunal de Justicia "CDC”, AEDIP, $\mathrm{t}$. XVI, 2016, p. 87. Vid., en este sentido, también, F.C. Haus/S.E. Erne, Transnational Indemnification Claims in national cartel cases, NZKart, vol. 16, no 8, 2016, p. 512.

26 STJUE de 27 abril 2017, Akzo, C-516/15P, ECLI:EU:C:2017:314, apartados 60 y 61; STJUE de 10 abril 2014, Siemens Österreicht, C-231/11P y C-233/11P, ECLI:EU:C:2014:256, apartado 45. En este último caso, el Tribunal de Justicia afirma que "Así pues, de reiterada jurisprudencia resulta que el comportamiento de una filial puede imputarse a la sociedad matriz, en particular, cuando, aunque tenga personalidad jurídica separada, esa filial no determina de manera autónoma su conducta en el mercado sino que aplica, esencialmente, las instrucciones que le imparte la sociedad matriz, teniendo en cuenta concretamente los vínculos económicos organizativos y jurídicos que unen a esas dos entidades jurídicas (véase, en particular, la sentencia Comisión/Stichting Administratiekantoor Portielje, antes citada, apartado 38 y jurisprudencia citada)." (apartado 46).

27 A.L. Calvo Caravaca/J. Carrascosa GonzÁlez, El Derecho Internacional privado de la Unión Europea frente a las acciones por daños anticompetitivos, $C D T$, vol. 10, $\mathrm{n}^{\circ} 2,2018$, p. 73

${ }^{28}$ C. Fratea, Los primeros pronunciamientos del Tribunal de Justicia de la Unión sobre Europea la aplicación privada del Derecho de la competencia y sus reflejos sobre la competencia judicial en las acciones indemnizatorias en Europa, AEDIP, $\mathrm{t}$. XVI, 2016, p. 645; F.C. Haus/S.E. ERne, Transnational Indemnification Claims in national cartel cases, NZKart, vol. 16, $\mathrm{n}^{\circ} 8$, 2016, p. 512.

Reglamento (UE) no 1215/2012 del Parlamento Europeo y del Consejo, de 12 diciembre 2012, relativo a la competencia judicial, el reconocimiento y la ejecución de resoluciones judiciales en materia civil y mercantil, DO L351, de 20 diciembre 2012.

${ }^{29}$ STJUE 23 octubre 2014, flyLAL-Lithuanian Airlines, C-302/13, ECLI:EU:C:2018:533, apartado 38.

A.L. Calvo Caravaca/J. Carrascosa GonzÁlez, El Derecho Internacional privado de la Unión Europea frente a las acciones por daños anticompetitivos, CDT, vol. 10, $\mathrm{n}^{\circ} 2,2018$, p. 42.

${ }^{30}$ E. CASTellanos RUIZ, International jurisdiction in damages actions for breach of antitrust law, La aplicación privada del Derecho de la competencia, Lex Nova, 2011, pp. 603-634; A.L. CAlvo CaravaCa/J. CARrascosa GonzÁlez, El Derecho Internacional privado de la Unión Europea frente a las acciones por daños anticompetitivos, CDT, vol. 10, no 2, 2018, pp. 43 y ss. 


\section{A. Reglamento 1215/2012: foro de sumisión}

19. Foro de sumisión expresa (art. 25). En primer lugar, hay que tener en cuenta la posible sumisión de las partes, la empresa infractora y la víctima del daño, a determinados tribunales europeos ${ }^{31}$. Esta sumisión puede ser expresa o tácita. Será expresa cuando las partes lo hayan pactado expresamente (art. 25). Será tácita cuando pueda deducirse del comportamiento de las mismas (art. 26). En ambos casos, el legislador hace prevalecer la voluntad de las partes y, así, les ofrece seguridad jurídica ${ }^{32}$.

Es claro que es posible la sumisión en litigios de daños que surgen de ilícitos antitrust, sin embargo, los autores observan varios escenarios en los que puede existir tensión entre la admisibilidad de estos acuerdos atributivos de competencia y el principio de aplicación efectiva del Derecho de la competencia en la Unión Europea ${ }^{33}$.

20. A través del foro de sumisión, como acaba de mencionarse, el legislador europeo pone en valor la autonomía de la voluntad de las partes. El acuerdo de sumisión supone que los tribunales competentes, de forma exclusiva, sean los elegidos por ellas. El elemento fundamental que justifica la competencia de los tribunales escogidos por las partes es el consentimiento, emitido de forma válida, por ellas $^{34}$. Nadie puede ser llevado ante una jurisdicción incompetente sin su consentimiento.

21. Según el artículo 25 del Reglamento, el acuerdo de sumisión puede adoptar cualquiera de las tres formas recogidas en el precepto. Por un lado, puede constar por escrito o ser alcanzado de forma verbal con confirmación escrita posterior. También puede haberse celebrado según los hábitos que tengan establecidos las partes. Por último, puede haberse concretado conforme a los usos que sean ampliamente conocidos en el sector del comercio en el que se inserte el contrato.

22. La sumisión puede realizarse a los tribunales de un Estado miembro en general, o a un concreto tribunal de un Estado europeo. En consecuencia, es un foro de competencia judicial internacional y de competencia judicial interna.

Puede acordarse antes del surgimiento del litigio entre las partes, circunstancia que es la más normal, pero también puede pactarse cuando ya existe la controversia entre ellas. Por otro lado, no es válido el acuerdo si no se concreta a las disputas que puedan surgir de una determinada relación jurídica de las partes; no se puede realizar un acuerdo de sumisión global, sin circunscribirlo a una concreta relación jurídica ${ }^{35}$.

${ }^{31}$ STJUE 21 mayo 2015, Cartel Damage, C-352/13, ECLI:EU:C:2015:335, apartado 62. En esta sentencia, el Tribunal de Justicia afirma que es posible la sumisión en este marco de reclamación de daños por ilícitos antitrust. Vid., en este sentido, C. HeInZe, Los acuerdos atributivos de jurisdicción y la ejecución efectiva del Derecho de la competencia de la UE. Algunas precisiones sobre el alcance de los acuerdos de jurisdicción tras la sentencia del Tribunal de Justicia "CDC", AEDIP, t. XVI, 2016, pp. 84-85; A.L. Calvo Caravaca/J. CARrascosa GonzÁlez, El Derecho Internacional privado de la Unión Europea frente a las acciones por daños anticompetitivos, CDT, vol. 10, $\mathrm{n}^{\circ} 2,2018$, p. 44.

${ }^{32}$ C. Heinze, Los acuerdos atributivos de jurisdicción y la ejecución efectiva del Derecho de la competencia de la UE. Algunas precisiones sobre el alcance de los acuerdos de jurisdicción tras la sentencia del Tribunal de Justicia "CDC”, AEDIP, t. XVI, 2016, p. 82.

${ }^{33}$ C. HeInze, Los acuerdos atributivos de jurisdicción y la ejecución efectiva del Derecho de la competencia de la UE. Algunas precisiones sobre el alcance de los acuerdos de jurisdicción tras la sentencia del Tribunal de Justicia "CDC", AEDIP, t. XVI, 2016, p. 85. Según el autor, estos escenarios son dos. Por un lado, la sumisión puede limitar las posibilidades de tribunales competentes para la víctima, quien podría tener más opciones si no existiera el acuerdo al respecto. Por otro lado, el pacto atributivo de competencia puede ser fruto del abuso de posición de dominio de la empresa vendedora/proveedora.

${ }^{34}$ STJCE 14 diciembre 1976, Segoura, 25-76, Rec. 1876, p. 01851, ECLI:EU:C:1976:178, apartado 6; STJCE 14 diciembre 1976, Colzani, 24-76, Rec. 1976, p. 01831, ECLI:EU:C:1976:177, apartado 7; STJCE 6 mayo 1980, Porta-Leasing, asunto 784/79, Rec. 1980, p. 01517, ECLI:EU:C:1980:123, apartado 5; STJCE 20 febrero 1997, MSG, C-106/95, Rec. 1997, p. I-00911, ECLI:EU:C:1997:70, apartado 15; STJUE 21 mayo 2015, Jaouad El Majdoub, C-322/14, Rec. electrónica, ECLI:EU:C:2015:334, apartado 29; STJUE 7 julio 2016, Höszig, C-222/15, Rec. electrónica, ECLI:EU:C:2016:525, apartado 37; STJUE 28 junio 2017, Leventis y Vafeias, C-436/16, Rec. electrónica, ECLI:EU:C:2017:497, apartado 34.

Vid., también, A. L. Calvo Caravaca/J. Carrascosa González, Derecho Internacional Privado, vol. II, $18^{a}$ ed., Comares, 2018, p. 753.

${ }^{35}$ STJCE 10 marzo 1992, Duffryn, C-214/89, 1992 I-01745, ECLI:EU:C:1992:115, apartado 31. 
23. El pacto de sumisión expresa habitualmente se encuentra recogido en el contrato que une a las partes. Como ya hemos mencionado antes, la sumisión debe referirse a una determinada relación jurídica, y sólo a ella, no puede extenderse a relaciones anejas -efectos objetivos-. Cabría preguntarse, entonces, si el acuerdo de sumisión recogido en un contrato se puede extender a la responsabilidad extracontractual derivada del incumplimiento de las normas del Derecho de la competencia europeo, sabiendo que la interpretación y validez de la cláusula de sumisión se rige por sus propias reglas, que la ley que rige el contrato puede no ser la que determine la validez del acuerdo de sumisión ${ }^{36}$.

El Tribunal de Justicia de la Unión Europea ya se ha pronunciado al respecto. En la sentencia del caso Cartel Damage, el Tribunal de Luxemburgo considera que la cláusula de sumisión existente en un contrato no puede aplicarse a la responsabilidad extracontractual derivada del mismo, salvo que expresamente se haga constar en el acuerdo que se va a aplicar a este tipo de litigio por daños -conclusión criticada por parte de la doctrina ${ }^{37}{ }^{38}$. Por lo tanto, sólo en el extraño supuesto de que en la cláusula de sumisión se

${ }^{36}$ Los tribunales españoles estiman que la responsabilidad extracontractual no está incluida en el ámbito de aplicación de una cláusula de sumisión contenida en un contrato, por tanto, no puede considerarse que la elección de tribunal se refiera a asuntos de reclamación de daños. Así, el AAP de Madrid (Sección 10a), 29 junio 2010, núm. 173/2010, dispone que, "En consecuencia, el hecho de que la demandada sea una persona jurídica distinta de la que ha suscrito el contrato de transporte marítimo, así como el tipo de acción que se ejercita, cuya finalidad es la exigencia de responsabilidad extracontractual, en virtud de lo preceptuado en el artículo 1.902 C.Civil, conducen a considerar que la demandada no se encuentra vinculada al contrato celebrado entre la actora y "Maersk Line", no siendo, por tanto aplicable a la relación existente entre actora y demandada la cláusula $26^{a}$ de sumisión expresa a favor del Tribunal Superior de Justicia de Londres, incluida en el referido contrato".

La High Court of England and Wales, por su parte, también se pronunció en el asunto Provimi resolviendo la cuestión de la extensión o no de la cláusula de sumisión recogida en un contrato a la responsabilidad extracontractual derivada de la infracción del Derecho antitrust (sentencia de la High Court of England and Wales, 6 mayo 2003, Provimi).

El asunto Provimi trae causa de una entente llevada a cabo por varias empresas de vitaminas (Decisión de la Comisión de 21 de noviembre 2001, asunto COMP/E-1/37.512 -Vitaminas). Las trece empresas sancionadas eran fabricantes de vitaminas A, E, B1, B2, B5, B6, C, D3, H, ácido fólico, betacaroteno y carotínidos, y abastecían a la Comunidad y el EEE. Estas entidades acordaron fijar precios en el mercado y asignar cuotas de venta; además crearon un dispositivo de supervisión del cumplimiento de los acuerdos. El mercado afectado era el EEE, aunque la Comisión consideró que cada vitamina podría tener un mercado mundial. La Comisión descubrió diferentes acuerdos relativos a las distintas vitaminas, en los participaban diferentes empresas. La duración de la infracción depende del cartel del que hablemos, los acuerdos que más se extendieron en el tiempo estuvieron en vigor desde el año 1989 hasta el año 1999.

En el caso Provimi los demandantes reclaman una indemnización por los perjuicios sufridos por haber tenido que comprar vitaminas a un precio superior al que habría en el mercado de no haber existido la entente que infringía el Derecho europeo de la competencia. La compañía Trouw Germany interpuso demanda de reclamación de daños frente a la empresa Roche UK alegando el foro del artículo 2 del Reglamento 44. También actuó contra otras dos compañías suizas y para ello la empresa alemana utilizó el Convenio de Lugano, el artículo 6.1 en concreto. Por último, para demandar a Roche Germany utilizó el foro del litisconsorcio pasivo del artículo 6.1 del Reglamento 44 para atraer la competencia hacia Inglaterra. Esta compañía demandada, Roche Germany, alegó la sumisión expresa a los tribunales alemanes que existía en el contrato de compraventa, para que el foro del artículo 6.1 no pudiera funcionar. El tribunal inglés consideró que la cláusula de sumisión del contrato de compraventa no incluía en su ámbito de aplicación las reclamaciones por la infracción del Derecho europeo de la competencia, por ello entendió que no había sumisión y que podía entrar en juego el foro del artículo 6.1 para atraer la competencia a los tribunales ingleses.

Los argumentos que utilizó el tribunal inglés para excluir de la cláusula de sumisión la responsabilidad extracontractual fueron los siguientes (F.W. Bulst, The Provimi decision of the High Court: beginnings of private antitrust litigation in Europe, European Business Organization Law Review, 4, 4, 2003, pp. 623-650). En primer lugar, el órgano jurisdiccional inglés considera que los tribunales elegidos en el pacto de sumisión no son competentes para dirimir asuntos de este tipo, derivados de la vulneración del Derecho antitrust. En segundo lugar, los daños reclamados no pueden derivar de actuaciones fraudulentas. En el caso en cuestión, el tribunal inglés considera que el contrato de compraventa con Roche Germany fue firmado en condiciones de engaño, ya que, la demandante acordó la compra considerando que el precio se había fijado en condiciones competitivas de mercado. En último lugar, un juez alemán consideraría que la reclamación de daños no está incluida en el ámbito de aplicación de la cláusula de sumisión puesto que puede entender que esta demanda de responsabilidad extracontractual no surge de la relación contractual entre las partes sino del hecho de que Roche Germany formaba parte de un cartel de precios ya antes de concluir el contrato de compraventa con la demandante.

${ }^{37}$ C. HeInze, Los acuerdos atributivos de jurisdicción y la ejecución efectiva del Derecho de la competencia de la UE. Algunas precisiones sobre el alcance de los acuerdos de jurisdicción tras la sentencia del Tribunal de Justicia "CDC", AEDIP, t. XVI, 2016, p. 89 ss.

${ }^{38}$ STJUE 21 mayo 2015, Cartel Damage, C-352/13, ECLI:EU:C:2015:335: “69. Atendiendo a ese objetivo, el tribunal remitente deberá considerar en especial que una cláusula que se refiere en abstracto a las controversias que surjan en las relaciones contractuales no abarca una controversia acerca de la responsabilidad delictual en la que hubiera incurrido supuestamente una parte contratante a causa de su conducta en el ámbito de un cártel ilícito. 70. En efecto, toda vez que tal litigio no era razonablemente previsible para la empresa perjudicada cuando dio su consentimiento a esa cláusula, pues desconocía 
haya pactado someter las reclamaciones por daños derivados de ilícitos antitrust ante unos determinados tribunales, y que éstos no sean ya competentes por otros foros del Reglamento -efecto de prórroga de la sumisión-, esos órganos jurisdiccionales elegidos podrán conocer de esas demandas por daños ${ }^{39}$.

24. Como puede comprobarse, aunque el Reglamento 1215/2012 designa el Derecho del Estado miembro cuyos tribunales han sido elegidos, como ley aplicable a la validez material del acuerdo de sumisión (art. 25.1 y Considerando 20), lo cierto es que el Tribunal de Justicia está configurando algunos criterios de determinación de la validez del mismo, como es, el que acaba de exponerse, esto es, que salvo concreción expresa, el acuerdo de sumisión recogido en un contrato no se extiende a los litigios de responsabilidad extracontractual derivados de la relación contractual ${ }^{40}$.

25. Foro de sumisión tácita (art. 26). La sumisión tácita se deduce del comportamiento de las partes $^{41}$. Esto es, las partes también pueden acudir, directamente, a unos tribunales concretos para interponer la demanda, la demandante, y contestar a la misma, la demandada. Así es, no es necesario que haya una concertación previa entre ellas con esa intención de someterse a determinada jurisdicción. La sumisión tácita se plantea en el momento en que surge el litigio, cuando el demandante acude a unos tribunales y el demandado contesta a la demanda ante esos órganos jurisdiccionales. No habrá sumisión tácita, sin embargo, cuando el demandado se oponga a la competencia del tribunal y, de forma subsidiaria, realice una defensa sobre el fondo del asunto ${ }^{42}$.

Por otra parte, según reiterada jurisprudencia, la sumisión tácita posterior prevalece sobre la expresa anterior ${ }^{43}$.

26. La sumisión expresa es difícil que concurra, ya que, es complicado que la víctima y el autor del comportamiento ilícito se pongan de acuerdo de forma expresa para acudir a determinados órganos jurisdiccionales. Sin embargo, es más probable que pueda existir sumisión tácita, esto es, es más fácil que el demandante interponga la demanda ante unos jueces europeos concretos y que el demandado conteste a la misma sin oponerse a la competencia del tribunal.

en ese momento el cártel ilícito en el que participaba la otra parte contratante, no se puede considerar que ese litigio tenga su origen en las relaciones contractuales. Por tanto, la referida cláusula no excluiría válidamente la competencia del tribunal remitente. 71. En cambio, ante una cláusula que hiciera referencia a las controversias sobre la responsabilidad incurrida a causa de una infracción del Derecho de la competencia y que designara a un tribunal de un Estado miembro diferente del Estado del tribunal remitente, éste debería declinar su propia competencia, incluso cuando esa cláusula lleve a excluir las reglas de competencia especiales previstas en los artículos 5 y/o 6 del Reglamento $n^{\circ}$ 44/2001."

A.L. Calvo Caravaca/J. Carrascosa González, El Derecho Internacional privado de la Unión Europea frente a las acciones por daños anticompetitivos, CDT, vol. 10, $\mathrm{n}^{\circ} 2,2018$, p. 52.

El Tribunal también ha estudiado los efectos personales de las cláusulas de sumisión, entendiéndolos limitados a las partes que han concluido el acuerdo de sumisión. No obstante, indica el Tribunal, podrían extenderse los efectos de la cláusula a terceros siempre que consientan en ello (apartado 64). Vid., en este sentido, C. Heinze, Los acuerdos atributivos de jurisdicción y la ejecución efectiva del Derecho de la competencia de la UE. Algunas precisiones sobre el alcance de los acuerdos de jurisdicción tras la sentencia del Tribunal de Justicia "CDC", AEDIP, t. XVI, 2016, pp. 86-88; A.L. CALvo CaravaCa/J. CARRASCosa GonZÁLEZ, El Derecho Internacional privado de la Unión Europea frente a las acciones por daños anticompetitivos, CDT, vol. $10, \mathrm{n}^{\circ} 2,2018$, pp. 62-64.

${ }^{39}$ C. Fratea, Los primeros pronunciamientos del Tribunal de Justicia de la Unión sobre Europea la aplicación privada del Derecho de la competencia y sus reflejos sobre la competencia judicial en las acciones indemnizatorias en Europa, AEDIP, $\mathrm{t}$. XVI, 2016, p. 663.

${ }^{40}$ C. HeInze, Los acuerdos atributivos de jurisdicción y la ejecución efectiva del Derecho de la competencia de la UE. Algunas precisiones sobre el alcance de los acuerdos de jurisdicción tras la sentencia del Tribunal de Justicia "CDC", AEDIP, t. XVI, 2016, p. 93-94.

El Considerando 20 del Reglamento indica que el Derecho del Estado miembro elegido por las partes, que se aplica a la validez material del acuerdo de sumisión, incluye las normas de conflicto.

${ }^{41}$ A.L. Calvo Caravaca/ J. Carrascosa González, El Derecho Internacional privado de la Unión Europea frente a las acciones por daños anticompetitivos, CDT, vol. 10, $\mathrm{n}^{\mathrm{o}} 2,2018$, pp. 66-71.

${ }^{42}$ STJCE 24 junio 1981, Elefanten, asunto 150/80, Rec. 1981, p. 01671, ECLI:EU:C:1981:148, apartado 17; STJCE 22 octubre 1981, Rohr, asunto 27/81, Rec. 1981, p. 02431, ECLI:EU:C:1981:243, apartado 8; STJCE 14 julio 1983, Gerling, asunto 201/82, Rec. 1983, p. 02503, ECLI:EU:C:1983:217, apartado 21.

${ }^{43}$ STJCE 24 junio 1981, Elefanten, asunto 150/80, Rec. 1981, p. 01671, ECLI:EU:C:1981:148, apartado 11; STJCE 7 marzo 1985, Spliztley, asunto 48/84, Rec. 1985, p. 00787, ECLI:EU:C:1985:105, apartado 26 


\section{B. Reglamento 1215/2012: foro general del domicilio del demandado y foro especial por razón de la materia}

27. No obstante lo dicho en relación con la sumisión tácita, lo más probable es que el tribunal competente lo sea por el foro general del domicilio del demandado o por el foro especial por razón de la materia. Ambos foros son alternativos y necesitan que el domicilio del demandado se encuentre en la Unión Europea para que puedan operar. Además, el foro especial sólo funciona cuando, encontrándose el domicilio del demandado en un Estado parte de la UE, designe como tribunales competentes a los de otro Estado miembro distinto.

28. Foro general del domicilio del demandado (art. 4). En virtud del foro general del domicilio del demandado los tribunales competentes son los que país de la Unión Europea en el que el demandado tenga su domicilio.

29. En el sector de la responsabilidad extracontractual por hechos lesivos del Derecho europeo de la competencia, los sujetos demandados sólo pueden ser empresas. En efecto, los artículos 101 y 102 TFUE sólo pueden ser infringidos por empresas, por lo tanto, en principio, sólo ellas podrían ser denunciadas por los daños ocasionados por ello.

Pues bien, desde este punto de vista, el domicilio que más se debe tener en cuenta es el de las personas jurídicas. El artículo 63 del Reglamento ofrece una definición material de este concepto. Según este precepto, la persona jurídica tendrá su domicilio en el Estado miembro en el que tenga la sede estatutaria, la administración central o el centro de actividad principal.

Estos tres conceptos de domicilio se corresponden con distintos elementos que conforman la empresa. Así, la sede estatutaria es la sede social, la que aparece en los estatutos de la compañía. La administración central es la sede real, desde donde se dirige la empresa. Y, por último, el centro de actividad principal es donde se desarrolla la actividad más relevante de la compañía.

Con la definición recogida en el artículo 63 del Reglamento es posible que la compañía tenga hasta tres domicilios en la Unión Europea y, por tanto, es posible que haya hasta tres tribunales competentes por este foro ante los que interponer la demanda de reclamación de daños.

30. En nuestro caso, son escasos los datos que ofrece el Auto, por lo que sólo podemos concluir en base a suposiciones. Si partimos del supuesto de que la demandada es una filial de una de las empresas responsables del comportamiento ilícito, el Juzgado de lo Mercantil de Madrid proporciona el dato del domicilio en España de aquella compañía, según el Reglamento 1215/2012. Por lo tanto, tal como concluye el órgano jurisdiccional, los tribunales españoles serían competentes por el foro general del domicilio del demandado.

Si considerásemos que la empresa demandada es la sucursal en España del Grupo Volvo, habría que saber dónde tiene su sede social, la administración central y el centro de actividad principal este Grupo al que demanda Carretillas Barcelona a través de la sucursal española. Según la Decisión de la Comisión Europea, el Grupo Volvo tiene su sede social en Suecia, por lo tanto, España no sería competente por el foro general del domicilio del demandado.

En este último caso, cabría preguntarse si sería posible alegar el foro especial de establecimientos secundarios para demandar en España al Grupo Volvo ${ }^{44}$. Para que dicho foro pudiera operar sería

\footnotetext{
44 "A este respecto, procede recordar que el Tribunal de Justicia ha identificado dos criterios que determinan si una acción judicial relativa a la explotación de una sucursal tiene conexión con un Estado miembro. En primer lugar, el concepto de "sucursal» implica la existencia de un centro de operaciones que se manifiesta de forma duradera hacia el exterior como la prolongación de una casa matriz. Ese centro debe estar dotado de una dirección y de un equipamiento material de manera que pueda negociar con terceros y estos no tengan que dirigirse directamente a la casa matriz. En segundo lugar, el litigio debe referirse bien a actos relativos a la explotación de una sucursal, bien a obligaciones contraidas por esta en nombre de la casa matriz, cuando esas obligaciones deban cumplirse en el Estado en que se encuentre dicha sucursal (véase, en este sentido, la sentencia de 19 de julio de 2012, Mahamdia, C154/11, EU:C:2012:491, apartado 48 y jurisprudencia citada)"' (STJUE 5 julio 2018, flyLAL-Lithuanian Airlines, C-27/17, ECLI:EU:C:2018:533, apartado 59)
} 
necesario que la sucursal española demandada hubiera intervenido de manera efectiva y significativa en el ilícito, fijando los precios de venta de los camiones, por ejemplo ${ }^{45}$.

31. Litisconsorcio pasivo (art. 8.1). Cuando se produce un ilícito del Derecho antitrust, en muchas ocasiones las empresas infractoras son varias. Así es, si nos situamos en el marco del artículo 101 TFUE tienen que ser varias las compañías que lleven a cabo una entente y lesionen el Derecho europeo de la competencia. Por otro lado, si lo hacemos en el marco del artículo 102 TFUE, si bien puede haber abuso de posición de dominio individual, también lo puede haber colectivo y, por ello, pueden ser dos o más empresas que infrinjan este precepto.

32. En estos supuestos, el artículo 8.1 permite la acumulación de competencias ante los tribunales del domicilio de uno de los demandados. En efecto, este precepto regula el litisconsorcio pasivo y ofrece la posibilidad al actor de acudir sólo a los tribunales del domicilio de uno de los demandados y allí demandar a todos los sujetos que han lesionado la competencia y han infligido daños.

Para que se abra esta posibilidad que ofrece el foro del artículo 8.1 Reglamento 1215/2012 es necesario que se cumplan dos requisitos. El primero de ellos es que todos los sujetos demandados ante el tribunal de uno de ellos tengan su domicilio en la Unión Europea. En segundo lugar, el TJCE, en el asunto Kalfelis, respondiendo a una cuestión prejudicial, afirmó que es necesario que exista una conexión suficiente entre las demandas planteadas ante los distintos demandados ${ }^{46}$.

Pues bien, el Tribunal de Justicia, en el asunto Cartel Damage ha considerado que sí existe esa vinculación que se exige a las demandas para que pueda operar el foro del litisconsorcio pasivo. Así, el órgano judicial afirma que "para la aplicación del artículo 6, punto 1, del Reglamento $n^{\circ}$ 44/2001 hay que verificar si entre las diferentes demandas presentadas por el mismo demandante contra distintos demandados existe un punto de conexión de tal naturaleza que haya interés en que sean resueltas conjuntamente, a fin de evitar soluciones que pudieran ser contradictorias si los litigios se juzgaran por separado" (apartado 20). El riesgo de resoluciones contradictorias existe desde el momento en que la víctima puede interponer demandas ante distintas jurisdicciones de los Estados miembros, debido a las diferencias en los Derechos nacionales en materia de responsabilidad civil que pueden existir en cada uno de los ordenamientos (apartado 22).

33. Foro especial por razón de la materia extracontractual (art. 7.2). El foro especial en estos supuestos de responsabilidad extracontractual se encuentra recogido en el artículo 7.2 del Reglamento. Este foro es aplicable en nuestro caso puesto que la demanda por daños derivados de un ilícito antitrust se encuentra incluida en la categoría de responsabilidad extracontractual ${ }^{47}$.

34. Lugar del hecho ilícito. Según este precepto, los tribunales competentes son los del lugar del Estado miembro en el que se haya verificado el hecho ilícito -foro de competencia judicial internacional y territorial ${ }^{48}$.

Este foro del lugar del hecho ilícito sólo puede utilizarse cuando la empresa contra la que se actúa sea parte en el litigio y haya llevado a cabo su comportamiento en el mercado del tribunal compe-

${ }^{45}$ STJUE 5 julio 2018, flyLAL-Lithuanian Airlines, C-27/17, ECLI:EU:C:2018:533, apartado 61.

${ }^{46}$ STJCE 27 septiembre 1988, Kalfelis, asunto 189/87, Rec. 1988, p. 05565, ECLI:EU:C:1988:459, apartados 11 y 12.

En este sentido, la High Court of England and Wales, en el asunto Provimi también se pronunció sobre la posibilidad de la aplicación de este foro, en el caso de la reclamación de daños y perjuicios contra las empresas del cartel de las vitaminas, ya mencionado. En este caso, el tribunal inglés consideró que sí había suficiente vinculación entre las demandas planteadas contra las distintas compañías puesto que las dos procedían de la misma infracción del artículo 81 TCE y poseían la misma naturaleza (F.W. Bulst, The Provimi decision of the High Court: beginnings of private antitrust litigation in Europe, European Business Organization Law Review, 4, 4, 2003, pp. 623-650).

47 J. Suderow, Acciones derivadas de ilícitos antitrust: el foro especial de la obligación extracontractual después de la sentencia CDC Hydrogen Peroxide, CDT, vol. 8, nº 2, 2016, pp. 313.

${ }^{48}$ C. Fratea, Los primeros pronunciamientos del Tribunal de Justicia de la Unión sobre Europea la aplicación privada del Derecho de la competencia y sus reflejos sobre la competencia judicial en las acciones indemnizatorias en Europa, AEDIP, t. XVI, 2016, p. 645. 
tente. Dicho de otra manera, si la empresa demandada no ha actuado en el Estado del foro, ese país no puede ser calificado como lugar del hecho ilícito ${ }^{49}$.

35. En estos casos de cárteles de empresas, el hecho dañoso es el ilícito antitrust y el lugar donde se produce es, según el Tribunal de Justicia de la Unión Europea, donde se haya celebrado el acuerdo colusorio ${ }^{50}$. Ese lugar de constitución del cártel puede ser casual y no presentar ninguna vinculación con el caso, puede, por ejemplo, no coincidir con el mercado afectado. Es más, en muchas ocasiones así será. Esta circunstancia resta previsibilidad y seguridad jurídica al foro ${ }^{51}$.

36. En muchos supuestos de ilícitos antitrust no se puede identificar un solo lugar de constitución del cártel. Así es, es muy habitual que haya varias reuniones entre los participantes en el acuerdo. En estos casos, tal como indica la jurisprudencia Besix, cuando el foro especial no permita determinar un único tribunal competente, porque serían varios en este escenario, no debería aplicarse ${ }^{52}$.

En el supuesto del Auto comentado hubo varias reuniones, por ejemplo. El Tribunal de Justicia, en estas circunstancias, individualiza el ilícito en relación con la víctima y, así, de este modo, indica que se puede entender constituido el cártel, a estos efectos de reclamación de daños, en el lugar de conclusión de un arreglo específico que por sí solo sea el hecho generador del perjuicio causado al comprador (apartado 46 de la STJUE Cartel Damage) ${ }^{53}$. Con los datos aportados en el Auto del Juzgado de lo Mercantil no se puede llegar a ninguna conclusión acerca de cuál es el lugar del hecho ilícito en este caso.

La doctrina critica que el Tribunal de Justicia no aporte ejemplos que puedan facilitar la labor de los jueces nacionales a la hora de identificar ese lugar de la reunión de la que se ha derivado el daño particular de la víctima demandante. Por esta razón, proponen que cuando haya varias reuniones y sea difícil, por tanto, determinar este lugar, se sustituya este foro por el del lugar de los efectos perjudiciales -lugar del daño- -54 .

37. Merece la pena destacar, por último, en relación con el lugar del hecho ilícito en estos casos, que el Tribunal de Justicia permite demandar a todos los miembros del cártel en virtud a este foro especial (STJUE Cartel Damage, apartado 50). En efecto, como ya hemos explicado, el Reglamento regula el litisconsorcio pasivo en el artículo 8.1 y lo hace tomando como base el foro general del domicilio del demandado. En el caso Cartel Damage, el Tribunal de Luxemburgo prescribe que se pueda demandar a

49 STJUE de 16 mayo 2013, Melzer, C-228/11, ECLI:EU:C:2013:305, apartado 40.

${ }^{50}$ STJUE de 21 mayo 2015, Cartel Damage, C352/13, ECLI:EU:C:2015:335, apartado 44. En jurisprudencia anterior, el Tribunal de Justicia prefirió optar por el lugar donde se producen los efectos perjudiciales (vid., en relación con esto, C. FRATEA, Los primeros pronunciamientos del Tribunal de Justicia de la Unión sobre Europea la aplicación privada del Derecho de la competencia y sus reflejos sobre la competencia judicial en las acciones indemnizatorias en Europa, AEDIP, t. XVI, 2016, p. 649 ss., p. 650).

En el supuesto de que el hecho ilícito fuera un abuso de posición de dominio, el órgano judicial europeo entiende que el lugar donde se verifica el hecho dañoso debe ser donde lleva a cabo el comportamiento ilícito. "En efecto, a diferencia del daño resultante de un acuerdo ilicito entre diversos participantes, el hecho causal que origina el daño en los casos de explotación abusiva de una posición dominante no se basa en un acuerdo, sino que reside en la puesta en práctica de esa explotación, es decir, en los actos llevados a cabo por la empresa dominante para ponerla en práctica, concretamente ofreciendo y aplicando precios predatorios en el mercado de que se trate" (STJUE 5 julio 2018, flyLAL-Lithuanian Airlines, C-27/17, ECLI:EU:C:2018:533, apartado 52).

${ }^{51}$ J. Suderow, Acciones derivadas de ilícitos antitrust: el foro especial de la obligación extracontractual después de la sentencia CDC Hydrogen Peroxide, CDT, vol. 8, n 2, 2016, p. 325. Vid., en este sentido, también, A. SARAVALLE, "Forum damni o fora damni?", Il Foro Italiano, no 11, noviembre, 1995, pp. 331-343.

${ }^{52}$ STJCE 19 febrero 2002, Besix, C-256/00, Rec. 2002 I-01699, ECLI:EU:C:2002:99, apartado 29; Conclusiones del Abogado General Sr. Niilo Jääskinen, presentadas el 11 de diciembre de 2014, al asunto C-352/13, ECLI:EU:C:2014:2443, apartado 52.

${ }^{53}$ C. Fratea, Los primeros pronunciamientos del Tribunal de Justicia de la Unión sobre Europea la aplicación privada del Derecho de la competencia y sus reflejos sobre la competencia judicial en las acciones indemnizatorias en Europa, AEDIP, $\mathrm{t}$. XVI, 2016, p. 653.

${ }^{54}$ C. FRATEA, Los primeros pronunciamientos del Tribunal de Justicia de la Unión sobre Europea la aplicación privada del Derecho de la competencia y sus reflejos sobre la competencia judicial en las acciones indemnizatorias en Europa, AEDIP, $\mathrm{t}$. XVI, 2016, p. 658. 
todos los autores del cártel ante los tribunales del lugar del hecho ilícito, cuando exista una Decisión de la Comisión declarando anticompetitivo el comportamiento ${ }^{55}$.

38. Lugar del daño: ilícitos a distancia. El foro especial en materia de responsabilidad extracontractual ha sido interpretado por el Tribunal de Justicia ampliando los tribunales que pueden ser competentes en su virtud. Así, en ilícitos a distancia, esto es, en supuestos en los que el hecho ilícito se verifica en un país y el daño en otro, los órganos jurisdiccionales competentes pueden ser, no sólo los del lugar del hecho ilícito -constitución del cártel-, también, los del lugar del daño -tesis de la ubicuidad ${ }^{56}{ }^{57}$.

39. El Tribunal de Justicia de la Unión Europea, en el asunto Cartel Damage, identifica el lugar del daño de la víctima, en principio, con el Estado donde se encuentra su domicilio social (apartado 52). En este punto, el Tribunal europeo aplica su jurisprudencia en el asunto eDate, relativo a vulneración de los derechos de la personalidad. En este caso eDate, el órgano judicial considera que el lugar del daño es el lugar del centro de intereses de la víctima, el cual coincidirá, habitualmente, con su residencia habitual ${ }^{58}$.

40 En nuestro caso, el daño se ha verificado en España, por lo tanto, si el demandado no tuviera su domicilio en nuestro país, nuestros tribunales serían competentes por este foro especial del lugar del daño $0^{59}$.

41. Daños plurilocalizados. En los casos de daños plurilocalizados, el hecho ilícito genera daños en diferentes Estados. El Tribunal de Justicia, siguiendo la jurisprudencia iniciada en el asunto Minas de Potasio, continuó estableciendo que el foro especial en materia de responsabilidad extracontractual determina que los tribunales competentes son los del lugar del hecho ilícito y, también, los del lugar del daño. Sin embargo, en estos casos de daños plurilocalizados ese lugar del daño no es único, hay varios lugares donde se verifican perjuicios. En este escenario, el órgano judicial europeo introduce la tesis del mosaico para afirmar que los distintos lugares del daño darán competencia a sus tribunales para conocer sólo del daño verificado en su jurisdicción ${ }^{60}$.

${ }^{55}$ La referencia del Tribunal de Justicia al presupuesto de la existencia de una Decisión de la Comisión en estos casos, lleva a la doctrina a entender que el litisconsorcio pasivo solo es posible en estos supuestos, esto es, en acciones follow on, ya sea con pronunciamiento previo de la Comisión o de cualquier autoridad nacional de competencia (C. FraTEA, Los primeros pronunciamientos del Tribunal de Justicia de la Unión sobre Europea la aplicación privada del Derecho de la competencia y sus reflejos sobre la competencia judicial en las acciones indemnizatorias en Europa, AEDIP, t. XVI, 2016, p. 660).

Vid., también, en este sentido de poder demandar a todos los autores del comportamiento ilícito ante los tribunales del foro especial, STJUE 5 julio 2018, flyLAL-Lithuanian Airlines, C-27/17, ECLI:EU:C:2018:533, apartado 42.

${ }^{56}$ A.L. Calvo Caravaca/J. Carrascosa González, Derecho Internacional Privado, vol. II, $18^{\mathrm{a}}$ ed., Comares, Granada, 2018, p. 1278.

${ }^{57}$ STJCE de 30 noviembre 1976, Minas de potasio, asunto 21-76, Rec. 1976, p. 01735, ECLI:EU:C:1976:166, apartado 24.

Vid., también, entre otras, STJCE de 11 de enero de 1990, Dumez France y Tracoba, C-220/88, Rec. 1990, p. I-00049, ECLI:EU:C:1990:8, apartado 17; STJCE de 19 septiembre 1995, Marinari, C-364/93, Rec. 1995, p. I-02719, ECLI:EU:C:1995:289, apartado 11; STJCE 5 febrero 2004, Torline, C-18/02, Rec. 2004, p. I-01417, ECLI:EU:C:2004:74, apartado 40; STJCE 10 junio 2004, Kronhofer, C-168/02, Rec. 2004, p. I-06009, ECLI:EU:C:2004:364, apartado 16; STJCE 16 julio 2009, Zuid-Chemie BV, C-189/08, Rec. 2009, p. I-06917, ECLI:EU:C:2009:475, apartado 23.

${ }^{58}$ STJCE 25 octubre 2011, eDate, C-509/09 y 161/10, Rec. 2011, p. I-10269, ECLI:EU:C:2011:685, apartados 48 y 49.

En este caso $e$ Date, en cambio, en ese lugar del centro de intereses de la víctima, como lugar del daño, el demandante puede reclamar todo el perjuicio sufrido; a diferencia de lo que ocurre con este foro en el resto de supuestos. Los autores consideran que debería aplicarse esta jurisprudencia del caso eDate en este punto también, además de exigir que el lugar del daño sea un mercado directa y sustancialmente afectado por la conducta ilícita y de permitir la acumulación de demandas en este foro. De esta manera, la doctrina extrapola el principio de unidad de ley, recogido en el artículo 6.II.b) del Reglamento Roma II, al sector de la competencia judicial internacional (J. SUDEROw, Acciones derivadas de ilicitos antitrust: el foro especial de la obligación extracontractual después de la sentencia CDC Hydrogen Peroxide, CDT, vol. 8, $\mathrm{n}^{\mathrm{o}}$ 2, 2016, pp. 326-327).

Reglamento (CE) no 864/2007, del Parlamento Europeo y del Consejo, de 11 julio 2007, relativo a la ley aplicable a las obligaciones contractuales (Roma II), DOUE L199, de 31 julio 2007.

59 J. Suderow, Acciones derivadas de ilícitos antitrust: el foro especial de la obligación extracontractual después de la sentencia CDC Hydrogen Peroxide, CDT, vol. 8, nº 2, 2016, p. 314.

${ }^{60}$ STJCE de 7 marzo 1995, Shevill, C-68/93, Rec. 1995, p. I-00415, ECLI:EU:C:1995:61, apartado 33.

En relación con la denominada tesis del mosaico, A.L. Calvo Caravaca/J. Carrascosa González, Derecho Internacional Privado, vol. II, $18^{\mathrm{a}}$ ed., Comares, Granada, 2018, p. 1294. 
De esta manera, la víctima tiene dos opciones. Por un lado, puede reclamar todos los daños sufridos, bien, ante los tribunales del domicilio del demandado, bien, ante los tribunales del lugar del hecho ilícito. Por otro lado, puede ir de jurisdicción en jurisdicción reclamando el daño sufrido en cada una de ellas.

42. En los comportamientos del Derecho antitrust es difícil encontrar un daño plurilocalizado. Si bien es cierto que una práctica restrictiva de la competencia puede afectar a varios mercados nacionales y producir daños en todos ellos, desde el punto de vista individual de la víctima, ésta sólo sufrirá daños en el país en el que ha comprado el producto o ha contratado el servicio. No obstante, se podría encontrar algún supuesto en el que sí podrían verificarse estos daños plurilocalizados. Así, ad ex., cuando la víctima es una empresa competidora que se ha visto perjudicada en los diferentes mercados nacionales afectados por la práctica restrictiva de la competencia - por haber tenido que abandonar esos mercados, ante la política agresiva de precios predatorios, por ejemplo-.

43. En nuestro caso, con los escasos datos que aporta el Auto del Juzgado de lo Mercantil de Madrid, puede deducirse que el demandante ha sufrido un único daño en España o, al menos, sólo demanda por ese daño ante nuestros tribunales. No estaríamos, por tanto, ante un supuesto de daños plurilocalizados y podrá demandar ante los órganos jurisdiccionales españoles el perjuicio total y único sufrido en nuestro país. 